\author{
HUMANASE SOCIAIS \\ V.8・N.2 • Agosto/Setembro/Outubro - 2019 \\ ISSN Digital: 2316-3801 \\ ISSN Impresso: 2316-3348 \\ DOI: 10.17564/2316-3801.2019v8n2p203-212
}
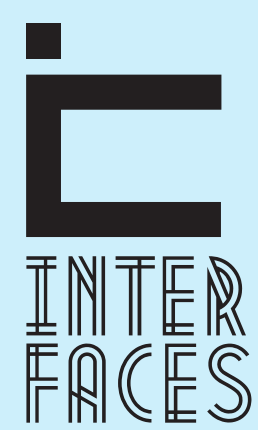

CIENTÍFICAS

\section{HISTÓRIAS (E)DITADAS: A MEMÓRIA NOS/DOS ARQUIVOS DO JORNAL NACIONAL, UM RECORTE DISCURSIVO}

EDITED STORIES: THE MEMORY OF THE NATIONAL JOURNAL ARCHIVES, A DISCURSIVE ANALYSIS

\section{HISTORIAS EDITADAS: LA MEMORIA EN LOS ARCHIVOS DEL JORNAL NACIONAL, UN ANÁLISIS DISCURSIVO}

\section{RESUMO}

Este artigo discute os conceitos de memória e arquivo a partir de um recorte da pesquisa de doutorado na área de Linguística. Fundamentada nos pressupostos teóricos-metodológicos da Análise do Discurso de filiação Pecheutiana, analisamos os efeitos de sentidos que atravessam o site Memória Globo, no que se refere aos arquivos do Jornal Nacional (JN), da TV Globo. O JN foi o primeiro telejornal exibido em rede nacional no Brasil, a partir de $1^{\circ}$ de setembro de 1969 , e é o que está há mais tempo em exibição na TV Brasileira, além de ser o programa de maior audiência entre os de conteúdo jornalístico.0 que nos interessa, sobremaneira, nessa pesquisa, são questões que apontam posicionamentos nas superfícies discursivas e que compõem a chamada "memória" do JN, envolvendo os principais eventos noticiosos em cada década, a partir de 1970 até 2010. Nosso movimento investigativo se debruça ao olharmos para o passado - memória/arquivo -, que insiste em ser guardado/apresentado à sociedade. Nesse sentido, buscamos em Michel Pêcheux as noções de memória e arquivo, buscando compreender que este não pode ser visto apenas como um frio banco de dados arquitetado por sujeitos que se anunciam com editores de histórias. É necessário considerar seu caráter histórico, cultural, político e ideológico. Desse modo, entendemos que o site Memória Globo, através de gestos seletivos, faz circular sentidos a partir de uma posição ideológica, que, em um movimento de lembrança, acaba apagando, a memória histórica, e, assim, silencia, ao mesmo tempo, sua posição política-empresarial.

\section{PALAVRAS-CHAVE}

Discurso. Telejornalismo. Memória. Arquivo. 


\section{ABSTRACT}

This article discusses the concepts of memory and archiving from a cut of the doctoral research in the area of Linguistics. Based on the theoretical-methodological assumptions of the Speech Analysis of Pecheutiana Affiliation, we analyze the effects of meanings that cross the Memória Globo website, in relation to the archives of Jornal Nacional (JN), of TV Globo. The JN was the first television newscast to be shown on Brazilian national television, starting on September 1,1969, and is the one that has been on the Brazilian TV for the longest time, as well as being the largest audience among journalists. What we are interested in, especially in this research, are questions that point to positions in the discursive surfaces and that make up the so-called "memory" of the JN, involving the main news events in each decade, from 1970 until 2010. Our investigative movement focuses when we look at the past memory / archive - that insists on being kept / presented to society. In this sense, we look for in Michel Pêcheux the notions of memory and archive, trying to understand that this can not be seen only as a cold database architected by subjects who advertise themselves with story publishers. It is necessary to consider its historical, cultural, political and ideological character. In this way, we understand that the Globo Memory site, through selective gestures, circulates meanings from an ideological position, which, in a movement of remembrance, ends erasing the historical memory, and thus silences, at the same time, its political-business position.

\section{KEYWORDS}

Speech. Telejornalismo. Memory. Archive.

\section{RESUMEN}

Este artículo discute los conceptos de memoria y archivo a partir de un recorte de la investigación de doctorado en el área de Lingüística. En el caso de los países de la región, los países de la Unión Europea (UE) y los países de la Unión Europea (UE). El JN fue el primer telediario exhibido en red nacional en Brasil, a partir del 1 de septiembre de 1969, y es lo que está hace más tiempo en exhibición en la TV Brasileña, además de ser el programa de mayor audiencia entre los de contenido periodístico. Lo que nos interesa, sobre todo, en esta investigación, son cuestiones que apuntan posicionamientos en las superficies discursivas y que componen la llamada “memoria” del JN, involucrando los principales eventos noticiosos en cada década, a partir de 1970 hasta 2010. Nuestro movimiento investigativo se centra al mirar al pasado - memoria / archivo -, que insiste en ser guardado / presentado a la sociedad. En ese sentido, buscamos en Michel Pêcheux las nociones de memoria y archivo, buscando comprender que éste no puede ser visto apenas como una base de datos frustrada, construida por sujetos que 
se anuncian con editores de historias. Es necesario considerar su carácter histórico, cultural, político e ideológico. De este modo, entendemos que el sitio Memoria Globo, a través de gestos selectivos, hace circular sentidos a partir de una posición ideológica, que, en un movimiento de recuerdo, acaba apagando, la memoria histórica, y así silencia, al mismo tiempo, su posición política-empresarial.

\section{PALABRAS CLAVE}

Discurso. Periodismo de televisión. Memoria. Archivo.

\section{INTRODUCÇÃO}

O presente artigo versa sobre um recorte do nosso corpus de pesquisa que está sendo desenvolvida no programa de Pós-Graduação em Letras e Linguística na Universidade Federal de Alagoas para a tese de doutorado desta pesquisadora. O foco central da tese é analisar e desvelar, a partir dos pressupostos teórico-metodológico da Análise do Discurso, filiada a perspectiva do filósofo francês Michel Pêcheux, os efeitos de sentido que atravessam o site Memória Globo, no campo referente aos arquivos do Jornal Nacional, da TV Globo de Televisão. 0 arquivo em análise nos possibilita compreender o olhar daquele que é considerado o mais importante telejornal da emissora sobre os fatos do cotidiano que foram escolhidos e selecionados para compor o que se denomina memória do programa.

Em nosso parâmetro de análise, o estudo do discurso jornalístico vai além do que estabelece o modelo focado na relação emissor/mensagem/receptor, modelo básico, tido como pré-requisito das comunicações humanas, esquema que fomenta um tratamento linear e pontual entre fontes, mensagens e receptores. Logo, não tratamos a comunicação como mera troca de informações Com isso, buscamos desvelar os efeitos de sentido que atravessam os arquivos selecionados para análise, considerando essa constituição do arquivo como uma prática, a partir dos termos de Pêcheux (2012, p. 24). Para o autor, prática é "todo processo de transformação de uma matéria-prima dada em um produto determinado, transformação efetuada por um trabalho humano determinado, utilizando meios de produção determinados". A partir da perspectiva em que nos ancoramos, o discurso é pensado enquanto estrutura e acontecimento, ou seja, seu funcionamento. Discurso como objeto teórico, compreendido como efeitos de sentido entre interlocutores e não como uma fala, uma transmissão de mensagens. Um objeto que apresenta regularidades e instabilidades podendo se apresentar através de diversas materialidades: sejam essas textuais, imagéticas ou multimodais.

Na contemporaneidade, é a Mídia um espaço significativo de observação dos discursos que circulam na sociedade. Entretanto, esse campo midiático é vasto, portanto, faz-se necessário delimitar e dizer sobre qual mídia estamos falando. Sendo assim, nossas reflexões se voltam prioritariamente para o discurso da/mídia jornalística. 


\section{ARQUIVO E MEMÓRIA: UMA RELAÇ̃O INDISSOCIÁVEL}

Da tela da TV para a rede mundial de computadores. Do que é efêmero para o que se pretende permanente, guardado na memória dos arquivos digitais, prontos para serem acessados. Esse é o caminho do arquivo que estamos explorando, no sentido de ir além das evidências do que está pronto para ser acessado.

Como dito anteriormente, o que nos interessa é analisar o gesto de escolha/edição que compõe o arquivo do programa Jornal Nacional da TV Globo de Televisão, e que selecionou o que se avaliou como principais acontecimentos noticiosos em cada década, a partir de 1970 até 2010. Para cada período, vários fatos jornalísticos foram arquivados como síntese da década em destaque. De outro modo, o arquivo do Jornal Nacional não traz as edições do telejornal na íntegra, isto é, de 1969 aos dias atuais. Neste grande arquivo digital, denominado Memória Globo, constam alguns textos e vídeos/reportagens, além de depoimentos de profissionais que fizeram parte do conteúdo selecionado. Um arquivo livre da poeira das estantes dos papéis guardados, um arquivo feito de bytes de memória metálica (ORLANDI, 2012).

Iniciamos nosso percurso situando o termo arquivo, "palavra que vem do grego arché, que, além de “início, “origem” e "autoridade”, significa "repartição pública” e "escritório público" (...). 0 arquivo está ligado desde o seu princípio com a escrita, a burocracia, a administração e os atos administrativos" (ASSMANN, 2011, p. 367). 0 autor ainda se refere ao arquivo como testemunha do passado, chamando-o de "armazenador coletivo de conhecimentos que desempenha diversas funções" (Idem, p. 368). Entre essas funções estaria a conservação, a seleção e a acessibilidade. No entanto, o próprio autor afirma que "os arquivos não são apenas locais para armazenamento de informação; são igualmente locais para as lacunas de informação...” (Idem). Ou, como nos coloca Dela-Silva (2016, p. 260), "um arquivo sempre é não-todo", isto é, faz-se necessário considerar o seu caráter de incompletude em todo arquivo a ser analisado. Incompletude própria da língua.

Antes de entrar e explorar o recorte do arquivo que escolhemos como parte de nosso corpus de pesquisa da tese, é importante compreender o que seria ler um arquivo discursivamente, ou seja, como analisamos um arquivo a partir de uma perspectiva discursiva ancorada nos pressupostos teórico-metodológicos do filósofo Michel Pêcheux.

Inicialmente, buscaremos no próprio Pêcheux a noção de Arquivo. Para o autor (2014, p. 59), essa noção deve ser "entendida no sentido amplo de campo de documentos pertinentes e disponíveis sobre uma questão", considerando sempre seu caráter histórico, cultural, político e ideológico. Queremos compreender os efeitos de sentido que atravessam os arquivos, observando o que foi selecionado, o que mereceu ser "guardado" no meio de tantos acontecimentos, assim como o que foi "esquecido", deixado de lado.

Segundo Magalhães e Silva Sobrinho (2014, p.125), não podemos ignorar que "todo arquivo é uma prática social constituída por gestos de interpretação que, como tal, tem como premissas as condições materiais de produção que permitiram sua efetivação e a ideologia predominante na sua elaboração", ou seja, o arquivo não pode ser visto apenas como um frio banco de dados arquitetado por sujeitos que se anunciam como editores de histórias. 
Sendo assim, nenhuma leitura do arquivo está dada a priori, o arquivo, assim como o discurso, é também lugar de interpretação porque, como diz Guilhaumou et. al.. (2016, p. 116): "o arquivo jamais é dado à primeira vista; seu regime de funcionamento é opaco”, cabendo ao analista desvelar essa opacidade de um funcionamento tido, muitas vezes, como evidente, claro e direto. É preciso questionar com se constroem certas evidências, apontar as contradições históricas e ideológicas no funcionamento do arquivo.

Relembrar, produzir, construir ou reconstruir o passado a partir de interesses sociais, políticos, culturais, considerando também que um arquivo pode ser um instrumento de poder e legitimação de discursos quando reconhecemos o seu caráter político.

Não há como falar de arquivo sem falar de memória - impossível separar - porque todo arquivo traz em si traços da memória produzindo uma rede de sentidos diversos. Ou, de outro modo, “a noção de arquivo está associada à memória, à conservação de algo, de maneira que não há como pensar um conceito sem relacioná-lo ao outro". (GALLI, 2011, p. 12). Na estruturação do arquivo em análise, o passado é lembrado e relatado por alguns sujeitos-jornalistas que tiveram participação nos assuntos selecionados. Ao falar de memória logo nos vêm sentidos de lembranças, reminiscências, recordações de experiências que se desejam ser perpetuadas, guardadas. No entanto, aqui, o papel da memória é ressignificado. Considerando a perspectiva em que nos ancoramos, cabe destacar que não tratamos da memória psicológica, da memória de um indivíduo que lembra e relata uma história.

Os discursos, ao circularem na sociedade, trazem uma memória de outros dizeres, ditos anteriormente, em outros lugares, em outras circunstâncias. Dizeres que Pêcheux (2009) denomina de interdiscurso, isto é, aquilo que fala antes, em outro lugar, independentemente, num movimento interferente e que se realiza de maneira incisiva dentro das relações sociais, num horizonte do já-dito, "interdiscurso como a memória que estrutura pelo esquecimento, à diferença do arquivo, que é o discurso documental, institucionalizado, memória que acumula” (ORLANDI, 2012, p. 59). Sem a memória, o sujeito não enuncia, pois, é a memória que se configura como um saber discursivo, como matéria essencial da linguagem.

\section{AS ORGANIZAÇ̃̃ES GLOBO E SEU PROJETO DE MEMÓRIA}

O discurso jornalístico trabalha na constituição de sentidos sobre a realidade, na tentativa de produzir efeitos de evidência, como se esses discursos fossem apenas transmissão de informação, isentos de quaisquer posicionamentos. No entanto, o discurso jornalístico, seja este falado, escrito ou/e imagético, veiculado por diferentes mídias, evidencia posições ideológicas a partir de uma indústria midiática que segue regras do mundo capitalista.

O site Memória Globo tem o conteúdo aberto, qualquer internauta/leitor pode acessá-lo, não precisando, assim, ser assinante. A entrada no arquivo do Jornal Nacional pode ser por ordem cronológica - digitando o ano de estreia do telejornal -1969- ou por ordem alfabética Neste artigo fizemos um recorte da parte inicial referente à primeira década do arquivo (1970/2010) do JN. Iniciando pelos 
anos 1970, o arquivo guarda/mostra três assuntos entre tantos outros que foram exibidos no JN, são eles: GREVES DO ABC, LEI DA ANISTIA e VOLTA DOS EXILADOS.

Para cada assunto, várias reportagens foram arquivadas, sempre acompanhadas de um texto sobre o arquivo resultando assim, numa materialidade verbo-visual. Entendemos esse texto como uma orientação de leitura, tentativa de direcionamento de sentidos para que o internauta/leitor faça determinado trajeto de exploração/leitura do que está sendo falado/mostrado, uma interpretação definida pelo verbal, pelos já-ditos (ORLANDI, 2012). Trazemos na sequência abaixo o texto que apresenta o assunto GREVES DO ABC:

SD: O fortalecimento do jornalismo da TV Globo paulista, no início dos anos 1980, foi favorecido pelo contexto da época, marcado por um sindicalismo forte e um empresariado ativo. São Paulo passou a ter cada vez mais espaço no noticiário nacional, sobretudo a partir das greves dos metalúrgicos do $A B C$ (região da grande São Paulo formada pelos municípios de Santo André, São Bernardo do Campo, São Caetano e Diadema). Apesar das restrições que o Jornal Nacional enfrentou para cobrir o tema em 1978, quando foi deflagrada a primeira greve, o assunto foi aos poucos ganhando destaque.(Grifos nossos)

Ao clicar em greves dos metalúrgicos do $A B C$, novos links vão surgindo numa sucessão de informações compostas sempre de textos que objetivam contar a história do movimento, mostrar a equipe e a estrutura da emissora, presente na cobertura jornalística, alguns destaques relacionados além de trazer uma lista de fontes com depoimento de profissionais da emissora que participaram direta ou indiretamente dos fatos arquivados.

Na SD acima, nos chama atenção, o enunciado “um sindicalismo forte e um empresariado ativo" porque, aparentemente, mostra um campo de forças equilibrado, no qual ambos os lados (patrões e empregados) teriam o mesmo espaço no telejornal. No entanto, essa primeira materialidade do arquivo nos traz alguns questionamentos, a saber: como uma emissora, (TV GLOBO), considerada um "braço simbólico" do governo militar, traz, no início do arquivo, como memória do seu principal telejornal (JN) as Greves do ABC? E ainda afirma que "o fortalecimento do jornalismo da TV Globo paulista, no início dos anos 1980, foi favorecido pelo contexto da época”, sendo esse assunto o primeiro a ser lembrado nos anos de 1970? Destacar esse assunto não seria um modo de silenciar o apoio da emissora ao Governo Militar? Ou como nos fala Orlandi, “dizer 'uma' coisa, para não deixar dizer 'outras'. Ou seja, o silêncio recorta o dizer. Esta é sua dimensão política” (1992, p.55). A própria memória discursiva tentando "apagar" a história, ou como bem colocou Pfeiffer, "para se dizer é preciso esquecer e é preciso apagar” (2007, p.169), apagar tudo aquilo que não se quer transformar em memória.

Nas reportagens sobre AS GREVES DO ABC, o destaque maior é para a figura do então líder sindical, presidente do Sindicato dos Metalúrgicos de São Bernardo do Campo, Luiz Inácio da Silva - o Lula, um dos líderes do movimento. Dos cinco vídeos arquivados, Lula vai aparecer em três deles e sempre com destaque, como porta-voz dos trabalhadores. Situação bem diferente da atualidade, em 
que a imagem do agora ex-presidente é sempre mostrada como culpado e o responsável maior pelos desmandos políticos e econômicos do país.

Em cada sessão do arquivo, um texto vai fornecer informações e explicações sobre a cobertura dos acontecimentos jornalísticos pela emissora. Nota-se uma necessidade de justificar a posição tomada pela emissora na época. As sessões acabam produzindo determinados sentidos e apagando outros. Ao fazerem circular certos discursos, buscam romper com certas memórias estabilizadas, memórias essas que perseguem a emissora ao longo de sua história. Uma dessas justificativas do posicionamento da emissora está presente na sequência abaixo:

SD: A equipe de jornalismo da Globo São Paulo acompanhou as paralisações de 1978, mas enfrentou restrições para cobrir o assunto. Armando Nogueira conta que os militares ordenaram à emissora uma coberturaleve, sem som ambiente e sem dar voz às lideranças sindicais. Isso provocou um grande descontentamento dos metalúrgicos, e a reação de alguns deles foi violenta. Grevistas ameaçaram incendiar a sede da Globo em São Paulo e chegaram a virar uma caminhonete de reportagem da emissora.

O jornalismo da Globo ganharia um pouco mais de liberdade para tratar da questão nos anos seguintes(...)

Mesmo com a justificativa de que os "militares ordenaram à emissora uma cobertura leve" na condução da cobertura jornalística, interessante perceber que, décadas depois, vivendo o país na chamada democracia, a emissora continua sendo alvo da ira de manifestantes. Os exemplos são inúmeros e variados, tais como este publicado pelo jornal Folha de S. Paulo, em sua edição online de 06/03/2016: "Cerca de 150 pessoas realizaram neste domingo(6) um protesto em frente à sede da Rede Globo, no Jardim Botânico, na zona sul do Rio. Os participantes criticaram a cobertura jornalística da emissora e defenderam o ex-presidente Luiz Inácio Lula da Silva”. Ou este outro, publicado na edição online do JB, de 31/03/2017: “Um protesto toma a entrada de uma das sedes da TV Globo, na Rua Jardim Botânico, na Zona Sul do Rio, desde a manhã desta sexta-feira (31), para lembrar o aniversário do Golpe Militar, no dia 31 de março de 1964, que instaurou por mais de 20 anos a ditadura no Brasil”. Os exemplos são muitos e, muitas vezes, a emissora é obrigada a emitir nota justificando seu posicionamento na cobertura dos fatos ou acusando os manifestantes de estarem cerceando o trabalho da imprensa. Essa volta de certas formulações "chama a atenção para o fato de que toda produção discursiva que se efetua nas condições determinadas de uma conjuntura movimenta - faz circular - formulações anteriores, já enunciadas" (COURTINE, 2009, p. 104).

Os temas seguintes da década em análise trazem textos e vídeos sobre a LEI DA ANISTIA e a VOLTA DOS EXILADOS que serão apresentados na próxima sequência:

SD: 0 general João Batista Figueiredo assumiu a presidência em março de 1979, com a tarefa de consolidar a transição democrática. Sua primeira medida foi sancionar, em 28 de agosto, a lei de anistia, aprovada pelo Congresso Nacional. No dia 29, o Jornal Nacional mostrou a libertação de presos políticos em Recife, Salvador, Rio e São Paulo. Nos dias seguintes, o JN acompanhou também 
a volta dos exilados. Um dos primeiros foi Fernando Gabeira, que chegou ao aeroporto do Rio em $1^{\circ}$ de setembro, quatro dias após a promulgação da lei. Em seguida, seria a vez de Leonel Brizola, Márcio Moreira Alves, Miguel Arraes e Luís Carlos Prestes.

Na SD acima, ao clicar na frase grifada/link, somos levados a assistir a treze vídeos sobre a chegada dos exilados nos aeroportos e a liberação de presos políticos no país. Em seguida, pode-se acessar a contextualização dos assuntos através de um texto explicativo sobre o processo de abertura política que começava a acontecer no país. Era o ano de 1979, governo do ex-chefe do Serviço Nacional de Inteligência, antigo SNI, general João Batista Figueiredo, último presidente do regime militar. São essas as condições postas para a compreensão do arquivo destacado. No entanto, se faz necessário promover uma desnaturalização do que está posto, pois, se todo discurso é essencialmente ideológico, o discurso sobre o arquivo também o é.

\section{CONSIDERAÇOES FINAIS}

Entendemos que existe um discurso sobre o arquivo audiovisual, discurso esse materializado nos textos que acompanham os vídeos. Estes não estão soltos, existe um direcionamento de leitura, de interpretação. Pois, os sentidos podem ser outros, mas não podem ser qualquer um, o sentido "não está já fixado a priori como essência das palavras, nem tampouco pode ser qualquer um: há a determinação histórica" (ORLANDI, 2012, p.27).

De acordo com Mariani (1998, p.30), a prática discursiva jornalística "permite a institucionalização social de certos sentidos, remetendo 'ao que todo mundo sabe' (uma verdade local)”, bem como silencia outros sentidos. Um silêncio de sentidos que nos remete ao pensamento de Orlandi quando afirma que 0

silêncio que atravessa as palavras, que existe entre elas, ou indica que o sentido pode sempre ser outro, ou ainda que aquilo que é o mais importante nunca se diz, todos esses modos de existir dos sentidos e do silêncio nos levam a colocar que o silêncio é "fundante" (1992, p.14).

Quantos assuntos não são deixados diariamente de fora de uma edição de um telejornal ou de um jornal impresso, muitas vezes com a justificativa de que não se "encaixam" nos critérios elementares de importância da notícia, mas que, de fato, foram silenciados como se nunca tivessem existido? A mesma "ausência" também pode ser observada nos arquivos, onde muitos assuntos são simplesmente ignorados, como se nunca tivessem sido relatados. São esses critérios que nos levam a refletir sobre as escolhas dessas histórias (e)ditadas em um arquivo de memórias através de um gesto de seleção que faz circular recortes do JN a partir de uma posição ideológica, que, em um gesto de lembrança, acaba apagando a memória histórica. E assim, silencia, ao mesmo tempo, tentando, a nosso ver, silenciar sua posição político-empresarial. 


\section{REFERÊNCIAS}

ASSMANN, Aleida. Espaços de recordação: formas e transformações da memória cultural. Campinas, SP: Editora da Unicamp, 2011.

COURTINE,J.J. Análise do discurso político: o discurso comunista endereçado aos cristãos. São Carlos: EdUFSCar, 2009.

DELA-SILVA, Silmara. Do acontecimento jornalístico e do arquivo: efeitos do/no discurso. In: GRIGOLETTO, E. e De Nardi, F.S. (Org.). A análise do discurso e sua história: avanços e perspectivas. Campinas, SP: Pontes Editores, 2016.

GALLI, Fernanda C.S. Deslizamento de sentidos em e na rede. In: AZEVEDO, N.P.S.G e FONTE, R.F.l. Análise do Discurso: movimento de interpretação.Curitiba, PR: CRV, 2011

MAGALHÃES, B. e SILVA SOBRINHO, H.F.“Lembrar” para esquecer: cinquenta anos do golpe de 1964. Comunicaçãoapresentada no II SEPLEV: Seminário de Estudos em Práticas de Linguagem e Espaço Virtual, Recife/PE, 2014.

MARIANI, Bethania. O PCB e a imprensa: os comunistas no imaginário dos jornais 1922-1989. Rio de Janeiro: Revan; Campinas/SP, UNICAMP, 1998.

ORLANDI, Eni. Discurso em Análise: Sujeito, sentido e Ideologia. Campinas/SP: Pontes, 2012.

ORLANDI, Eni. Interpretação: autoria, leitura e efeitos do trabalho simbólico. Campinas, SP: Pontes Editores, 2012.

ORLANDI, Eni. As formas do silêncio: no movimento dos sentidos. Campinas/SP: Ed. UNICAMP, 1992

PÊCHEUX, Michel. Ler o arquivo hoje. In: ORLANDI, E.P. (Org.). Gestos de leitura: da história no discurso. $4^{\mathrm{a} e d}$. Campinas, SP: Editora da Unicamp, 2014.

PÊCHEUX, Michel. Papel da memória. . In: ACHARD, P. et al. Papel da memória. Campina, SP: Pontes Editores, 2010.

PÊCHEUX, Michel. Semântica e Discurso: uma crítica à afirmação do óbvio. Campinas/SP: Editora da Unicamp, 2009. 
PFEIFFER, Cláudia Castellanos. O fogo que desengessa e mobiliza - uma entrada na obra de Michel Pêcheux. In: Michel Pêcheux e Análise do Discurso: uma relação de nunca acabar. São Carlos: Claraluz, 2007.
Recebido em: 30 de Abril de 2019

Avaliado em: 6 de Agosto de 2019

Aceito em: 7 de Agosto de 2019

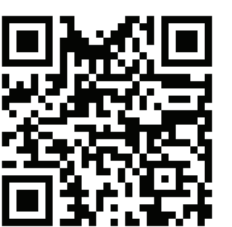

A autenticidade desse artigo pode ser conferida no site https://periodicos. set.edu.br
1 Professora do Centro Universitário Tiradentes/UNIT-AL; Mestre e doutoranda em Letras e Linguística pela Universidade Federal de Alagoas.

E-mail: rachel fiuza@hotmail.com.

Tese a ser defendida em dezembro de 2019 (Título: HISTÓRIAS (E)DITADAS: um arquivo que se quer memória

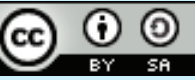

Este artigo é licenciado na modalidade acesso abertosob a Atribuição-Compartilhalgual CC BY-SA

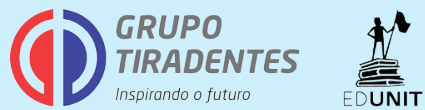

